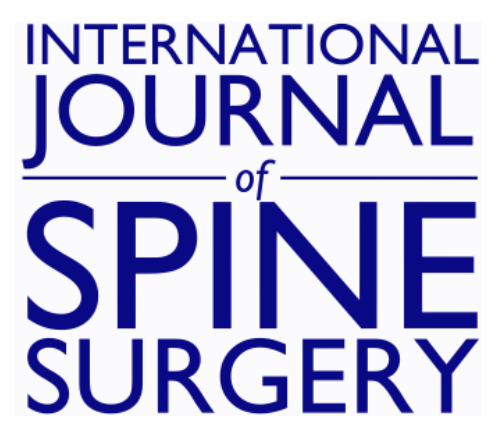

\title{
Demineralized Bone Matrix in Spine Surgery: A Review of Current Applications and Future Trends
}

Nicholas A. Shepard, Augustus J. Rush III, Nelson L. Scarborough, Andrew J. Carter and Frank M. Phillips

Int J Spine Surg 2021, 15 (s1) 113-119

doi: https://doi.org/10.14444/8059

http://ijssurgery.com/content/15/s1/113

This information is current as of April 26, 2023.

Email Alerts Receive free email-alerts when new articles cite this article. Sign up at:

http://ijssurgery.com/alerts

The International Journal of Spine Surgery

2397 Waterbury Circle, Suite 1,

Aurora, IL 60504, Phone: +1-630-375-1432 


\title{
Demineralized Bone Matrix in Spine Surgery: A Review of Current Applications and Future Trends
}

\author{
NICHOLAS A. SHEPARD, MD, ${ }^{1}$ AUGUSTUS J. RUSH III, MD,${ }^{1}$ NELSON L. SCARBOROUGH, PHD, ${ }^{2}$ \\ ANDREW J. CARTER, PHD ${ }^{2}$ FRANK M. PHILLIPS, MD $^{1}$ \\ ${ }^{I}$ Department of Orthopaedic Surgery, Rush University Medical Center, Chicago, Illinois ${ }^{2}$ TheraCell, Inc, Sherman Oaks, California
}

\begin{abstract}
Background: Graft augmentation for spinal fusion is an area of continued interest, with a wide variety of available products lacking clear recommendations regarding appropriate use. While iliac crest autograft has long been considered the "gold standard", suboptimal fusion rates along with harvest-related concerns continue to drive the need for graft alternatives. There are now multiple options of products with various characteristics that are available. These include demineralized bone matrix (DBM) and demineralized bone fibers (DBF), which have been used increasingly to promote spine fusion. The purpose of this review is to provide an updated narrative on the use of DBM/DBF in spine surgery.

Methods: Literature review.

Results: The clinical application of DBM in spine surgery has evolved since its introduction in the mid-1900s. Early preclinical studies demonstrated its effectiveness in promoting fusion. When used in the cervical, thoracic, and lumbar spine, more recent clinical data suggest similar rates of fusion compared with autograft, although clinical studies are primarily limited to level III or IV evidence with few level I studies. However, significant variability in surgical technique and type of product used in the literature limits its interpretation and overall application.

Conclusions: DBM and DBF are bone graft options in spine surgery. Most commonly used as graft extenders, they have the ability to increase the volume of traditional grafting techniques while potentially inducing new bone formation. While the literature supports good fusion rates when used in the lumbar spine and when used with adjuvant cages or additional grafting techniques in the cervical spine, care should be taken when using as a stand-alone product. As new literature emerges, DBM and DBF can be a useful method in a surgeon's armamentarium for fusion-based procedures.
\end{abstract}

Special Issue

Keywords: demineralized bone matrix (DBM), spine surgery, lumbar fusion, cervical fusion, biologics

\section{INTRODUCTION}

The need for bone grafting has been recognized for centuries and has undergone significant advancements from biological and clinical perspectives. The mechanisms of bone formation have been elucidated over time and have guided the use and development of bone grafts. Early descriptions of bone grafting by the Dutch surgeon à Meek'ren ${ }^{1}$ included transplantation of xenograft dog bones. In 1881, Macewen ${ }^{2}$ speculated that osteoblasts within autografts contributed to their success, an early acknowledgment of osteogenesis as a cellular component to bone repair. In the late 1880 s, Senn ${ }^{3}$ processed tibiae in hydrochloric acid, resulting in bone demineralization, and implanted the demineralized bone for the treatment of osteomyelitis. Since these early predecessors to bone grafting, there has been increased interest in the use of autograft, allograft, and synthetic alternatives to promote bone healing and fusion. This is especially true in spine surgery, where adequate bone fusion is essential to clinical success.

Iliac crest bone graft (ICBG) has long been considered the "gold standard" graft source for fusion-based procedures. Advocates for ICBG cite availability from the patient, low cost, and favorable biologic characteristics. However, increased operative time needed for graft harvest, graft site morbidity, and associated blood loss have been reported. ${ }^{4}$ Additionally, autograft quality depends on many factors, including patient age, health, graft harvest methods, and donor site. This has led to the development of a wide range of commercially available bone graft alternatives, including demin- 
eralized bone matrix (DBM) and demineralized bone fibers (DBF).

The purpose of this review is to highlight the bone healing principles associated with successful grafting, evaluate the roles of DBM and DBF in spine surgery based on review of the relevant preclinical and clinical evidence, and to provide insight on current trends in the development of improved DBM and DBF technology.

\section{DBM PROPERTIES}

DBM is common in clinical use, accounting for up to $50 \%$ of allografts used in the United States. ${ }^{5}$ While there are multiple suppliers, products, and formulations, DBM is generally produced from allograft cortical bone that is cleaned and ground into particles, typically between $250-750 \mu \mathrm{m}$. The particles are then treated with dilute $(0.5-0.6 \mathrm{~N})$ hydrochloric acid to remove the mineral component of the bone, leaving the collagen matrix and other proteins, including bone morphogenetic proteins (BMPs) and other growth factors. The collagen matrix and biologic components of DBM, particularly BMPs, are critical to its use as a bone graft and allow it to be used as a graft extender with osteoinductive properties (Table 1). Since DBM is derived from human allograft bone, there is the potential for disease transmission via DBM grafting, although no cases of disease transmission have been reported in the literature. ${ }^{6}$ Similarly, donor bone allograft could induce immunogenicity with a potential effect on the biogenic properties of DBM. ${ }^{6}$

In his landmark paper, Marshall Urist described bone formation by autoinduction based on his observation that DBM stimulated new bone formation when implanted into nonboney sites in rats. ${ }^{7}$ This led to the concept of osteoinduction, BMPs, and the process of bone morphogenesis promoted by growth factors discovered within DBM. ${ }^{4}$ Removal of the mineral component unmasks these inherent biologic characteristics and results in the osteoinductive properties of DBM, which are not demonstrated by cortical or cancellous allograft. ${ }^{8}$

The properties of DBM, however, are greatly dependent on the method of DBM preparation. This includes the demineralization processing techniques (eg, solvent, temperature, duration of demineralization, and concentration of active components), sterilization methods (eg, gamma irradiation), storage conditions (eg, temperature), and donor age. Likely, given this variability, the overall quantity of BMPs and other growth factors important in the osteoinductive nature of DBM has been noted to vary vastly between products. 9,10 These factors help to explain some of the discord between the preclinical and clinical data surrounding the DBM's osteoinductive potential.

An ideal graft would be easily manipulated intraoperatively, avoid graft migration, readily incorporate, and provide sufficient mechanical strength to support fusion. Early DBM particulate grafts were difficult to handle intraoperatively and difficult to maintain within the graft site due to graft size and the potential to migrate from the implanted site. Recognizing this, O'Leary and McBrayer combined DBM with glycerol, a carrier substance, to create a viscous gel form, which improved the ability to deliver the graft to the surgical site. ${ }^{11}$ The success of this tissue-engineered form of DBM (Grafton Gel) invited multiple alternatives with varying types of carrier formulations. There are currently numerous variants of DBM products with excipients available on the market.

The ability to easily deliver DBM putty products to the grafting site improved handling, but did not solve the problems of graft migration and the ability to resist compression at the graft site. To address these limitations, Dowd and Dyke ${ }^{12}$ described a material comprising a coherent mass of elongated, mechanically entangled demineralized bone. The ability to produce elongated bone fibers that could be formed into a putty, strip, or other shape further improved handling properties, avoided graft migration, and offered compression resistance. This new form of DBM, demineralized bone fibers (DBF), has been demonstrated to have similar osteoinductive potential as particulate DBM in preclinical studies, but has an enhanced osteoconductive capability due to its elongated shape and resulting interconnected matrix.

The enhanced osteoconductive performance of DBF was demonstrated in a rabbit posterolateral fusion model by Martin et al. ${ }^{13} \mathrm{DBM}$ and DBF were implanted alone or as a 50:50 mix with iliac crest autograft and were noted to have improved fusion rates with autograft supplementation and outperformed the autograft group. To better understand this phenomenon, noncollagenous proteins (ie, BMPs) were extracted to remove the osteoinductive component, converting the grafts into strictly osteoconductive matrices. This treatment eliminated the fusion response of the DBM 
Table 1. Mechanisms of bone healing and properties of bone graft options.

\begin{tabular}{|c|c|c|c|}
\hline Property & Description & Key Graft Properties & Graft Options \\
\hline Osteoconduction & $\begin{array}{l}\text { Ability of graft scaffold to support bone } \\
\text { ingrowth throughout the matrix to } \\
\text { achieve bridging and fusion }\end{array}$ & $\begin{array}{l}\text { Porous, interconnected structure; surface } \\
\text { texture and chemistry } \\
\text { Ability to be remodeled and replaced by } \\
\text { new bone }\end{array}$ & Cancellous allograft, DBF \\
\hline Osteoinduction & $\begin{array}{l}\text { Ability to recruit and stimulate } \\
\text { differentiation of osteoprogenitor/stem } \\
\text { cells into osteoblastic lineage }\end{array}$ & $\begin{array}{l}\text { New bone formation in nonboney sites } \\
\text { or remote from viable host bone } \\
\text { within the graft mass (eg, along } \\
\text { peripheral muscle contact or center of } \\
\text { graft) }\end{array}$ & BMPs, DBM, DBF \\
\hline Osteogenesis & $\begin{array}{l}\text { New bone formation by living bone cells } \\
\text { within the site or from autograft }\end{array}$ & $\begin{array}{l}\text { Viable, plentiful osteogenic cell } \\
\text { population. Bone marrow-rich, } \\
\text { cancellous, and bleeding decorticated } \\
\text { bone }\end{array}$ & ICBG, BMA, local bone, decorticate \\
\hline
\end{tabular}

Abbreviations: BMA, bone marrow aspirate; BMPs, bone morphogenetic proteins; DBF, demineralized bone fibers; DBM, demineralized bone matrix; ICBG, iliac crest bone graft.

particulate, but the DBF fibers were still able to support fusion in $30 \%$ of animals. From these data, it was concluded that DBF have a greater osteoconductive performance than DBM particulate, with the proposed mechanism being that osteoblasts are better able to migrate along the DBF rather than transfer from one demineralized bone particle to the next.

\section{APPLICATIONS IN SPINAL SURGERY}

With modern spine surgery, the requirement for bone grafting has expanded significantly. Although iliac crest autograft is still considered the "gold standard", the use of allograft and synthetic grafts can reduce the need for graft harvest and its associated complications. Furthermore, there is a significant rate of failed fusions even with ICBG, ranging from $5 \%-50 \% .{ }^{14}$ Choreographing the mechanisms of bone healing and selecting the best bone graft option to maximize the chance of successful fusion is a persistent challenge for spine surgeons. Regardless of the type of graft used, using the native osteogenic capabilities of the surgical site via adequate graft site preparation, using available local autograft (LA), filling the defect so there is a continuous osteoconductive scaffold to support new bone formation, and incorporating osteoinductive capabilities of the graft material are crucial to their use.

\section{CLINICAL USE OF DBM/DBF IN THE LUMBAR SPINE}

Multiple articles have demonstrated the utility of DBM in lumbar fusion cases, specifically as an LA extender. ${ }^{15-23}$ One of the first articles evaluating the use of DBM in instrumented posterolateral fusion was a level III study by Sassard et $\mathrm{al}^{15}$ that compared the use of DBM (Grafton Gel) and LA with iliac crest bone grafting (ICBG) in 1, 2, and 3 level posterolateral fusion. This article demonstrated equivalent fusion rates (60\% DBM versus $56 \%$ ICBG, $P=.8$ ); however, no donor-site pain was reported in the DBM group compared with nearly $30 \%$ in the ICBG group.

A level I prospective randomized trial by Kang et $\mathrm{al}^{18}$ comparing efficacy of DBM (Grafton Matrix) and LA with ICBG in single-level posterolateral fusion showed similar results. No difference in fusion rates $(86 \%$ DBM versus $92 \%$ ICBG,$P>$ .99) were noted based on radiographic and computed tomography (CT) analysis at multiple time points. Similarly, there were no differences in Oswestry Disability Index and physical function scoring; however, this study was able to demonstrate decreased blood loss $(512 \mathrm{~mL}$ versus $883 \mathrm{~mL}$, $P=.0031)$ and a trend toward decreased operating time (200 min versus $226 \mathrm{~min}, P=.065$ ) in the DBM group. The authors were able to conclude that fusion rates and clinical outcomes with the use of DBM were comparable to ICBG in single-level lumbar surgery with the added benefit of decreased blood loss.

Fu et $\mathrm{al}^{24}$ were able to demonstrate similar results in a long fusion construct ( $>3$ levels) in a level III study from 2016. Twenty-six patients undergoing multilevel PLF using DBM putty (Allomatrix, Wright Medical) and LA and 21 control patients received multilevel PLF with ICBG and LA. Fusion rates were noted to be equivalent between the groups, $81 \%$ in the DBM group versus $86 \%$ in ICBG group $(P=.72)$, while blood loss was significantly less in the DBM group $(700 \mathrm{~mL}$ versus 
$1200 \mathrm{~mL}, P=.02$ ). This study also demonstrated a trend toward decreased operative time and hospitalization in the DBM group, although not statistically significant.

Baumann et $\mathrm{al}^{20}$ retrospectively reviewed the fusion rates of patients treated with ICBG versus DBM (Synthes; specific formulation not specified by article) and LA in the setting of PLF for acute thoracolumbar trauma. Fusion rates were found to be equivalent between the groups (94\% DBM versus $100 \% \mathrm{ICBG}, P=.26$ ). The authors were able to conclude that DBM as an LA extender has similar fusion rates to ICBG in the treatment of thoracolumbar fractures.

A level III study from 2016 by Nam et $\mathrm{al}^{25}$ compared fusion rates and function outcome scores between DBM (Bonfuse, CG Bio Inc) and hydroxyapatite (HA) as LA extenders. No difference was found between the groups with respect to functional outcomes. The fusion rate at 1 year postoperation was found to be $73 \%$ in the DBM group versus $58 \%$ in the HA group; however, this was not statistically significant $(P=.15)$. A similar 2018 study by Ricart et $\mathrm{al}^{26}$ compared DBM (Grafton) with another commonly used extender, $\beta$-tricalcium phosphate. Again, no statistically significant differences were noted between the two extenders; however, there was a trend toward a higher fusion rate with DBM (90\% versus $70 \%$ at 1 year, $P=.09)$ and a lower rate of revision in the DBM group ( $0 \%$ versus $15 \%)$.

Regarding interbody fusion, few studies have directly compared DBM with autograft in the lumbar spine. Kim et $\mathrm{al}^{27}$ compared HA-DBM (Bonfuse, CG Bio Inc.) alone with LA as a filler for interbody cages. No statistically significant difference in functional outcomes were noted at 12 months. Similarly, no statistically significant difference in fusion rate was noted on CT at 1 year $(52 \%$ DBM versus $62 \%$ LA, $P=.21)$. This study did demonstrate a correlation between older age and lower bone mineral density with pseudoarthrosis in the DBM group. The authors concluded that HADBM has similar fusion rates to LA as an interbody filler; however, older age and low bone mineral density are baseline risk factors for nonunion using HA-DBM. ${ }^{27}$

Ahn et $\mathrm{al}^{19}$ evaluated the use of DBM as an LA extender in PLIF cages. In a case control study, 70 patients had a PLIF with LA and 44 had a PLIF with local bone and DBM extender (Allomatrix). No difference was noted in Oswestry Disability
Index scores at 2-year follow-up. No significant difference was noted in the degree of bone formation between the groups at 2-year follow-up. There was evidence of enhanced bone formation at 6 months in the DBM group; however, this was suspected to be due to assessment flaw. The authors concluded that DBM did not present a graftenhancing effect when used as a composite graft in PLIF.

The use of DBM as a local autograft extender in lumbar procedures is well documented; however, there is a paucity of high-level data demonstrating superiority to other available graft extenders. In a systematic review comparing allograft with DBM as an LA extender in both instrumented and noninstrumented lumbar fusion cases, Buser et $\mathrm{al}^{28}$ concluded that DBM was superior to allograft in noninstrumented fusions, but provided similar fusion results in instrumented cases. This article may indicate the limitations of DBM in improving fusion results, especially with modern surgical techniques. However, it also indicates the need for better studies designed to directly compare DBM with other products. More recent articles have also come to question the use of DBM in certain situations, such as in the elderly and in patients with low bone mineral density. ${ }^{21,29}$ Further studies are needed to elucidate the use of DBM in these more specific circumstances.

An additional consideration when interpreting the clinical evidence regarding DBM in the lumbar spine is that fusion results are likely multifactorial and technique dependent. The ability of clinical studies to provide evidence to elucidate subtle performance characteristics between various bone graft technologies is limited by a number of factors, including patient variables, assessment tools, and limitations on control group treatments. Unfortunately, there is also a lack of detail regarding the bone graft and graft site preparation techniques used in many clinical reports. Kang et $\mathrm{al}^{18}$ is an example where these details were explicitly presented, allowing for a better understanding of the results.

\section{CLINICAL USE OF DBM/DBF IN CERVICAL SPINE FUSION}

The clinical use of DBM in the cervical spine is not as well defined compared with its clinical efficacy in lumbar fusion. The majority of literature consists of level II to level IV studies and focuses 
primarily on DBM as a graft extender. An early prospective study by An et $\mathrm{al}^{30}$ compared DBM (Grafton DBM Gel) with freeze-dried allograft to ICBG in uninstrumented anterior cervical fusions. The authors noted higher rates of pseudoarthrosis per level with DBM/allograft versus ICBG (33.3\% versus $22 \%, P=.23)$ as well as higher rates of graft collapse $(39.7 \%$ versus $24.4 \%, P=.09)$ at 12 months postoperatively. The use of additional plate fixation may help improve these outcomes. A retrospective study by Lee et $\mathrm{al}^{31}$ found similar fusion rates between cortical allograft with DBM (Orthoblast II) and ICBG when used with supplemental plate fixation (94.1\% versus $95.7 \%$, respectively).

More recently, clinical research has focused on the use of DBM in conjunction with an interbody spacer in anterior cervical procedures. Park et al ${ }^{32}$ prospectively followed 31 patients undergoing anterior cervical discectomy and fusion with polyetheretherketone (PEEK) cages supplemented with DBM (Grafton DBM gel). At 12 months, the authors noted fusion rates comparable to those with ICBG and significant improvements in visual analog scale (VAS) pain scores with no implant-related complications. Additional level IV studies have noted similar findings, with comparable fusion rates and clinical outcomes between iliac crest autograft and PEEK interbody devices supplemented with DBM. ${ }^{22,33}$

Two prospective randomized studies have analyzed the use of PEEK cages with DBM versus another grafting substrate. Xie et $\mathrm{al}^{34}$ studied 68 patients with cervical spondylosis undergoing anterior cervical discectomy and fusion (ACDF) with PEEK cages supplemented with either calcium sulfate and DBM or iliac cancellous autograft. At 12 months, fusion rates were lower in the calcium sulfate and DBM group than autograft (94.3\% versus $100 \%$ ); however, at 2 years, both groups achieved a $100 \%$ fusion rate. These findings were similar to those of Yi et $\mathrm{al}^{35}$ who compared ACDFs with PEEK cages filled with hydroxyapatite and either DBM or $\beta$-tricalcium phosphate. At 1-year follow-up, both groups had similar fusion on radiographs and $\mathrm{CT}$.

\section{CLINICAL USE OF DBM/DBF IN PEDIATRIC DEFORMITY}

Literature supporting the use of DBM in cases of pediatric deformity is sparse, with few level IV studies assessing its use in fusion for scoliosis. One retrospective study by Price et $\mathrm{al}^{36}$ compared three grafting options for adolescent idiopathic scoliosis: autologous iliac crest, cortiocancellous allograft, and DBM (formulation not specified) with bone marrow aspirate. The authors noted similar fusion rates between autogenous grafting and DBM with bone marrow aspirate, and significantly lower fusion rates with cortiocancellous allograft. Similar findings were noted by Weinzapfel et $\mathrm{al}^{37}$ who retrospectively reviewed the use of DBM (Grafton DBM Flex) versus cortiocancellous allograft for patients undergoing video-assisted thorascopic fusion for idiopathic scoliosis. At final follow-up, 92\% of levels were fused with DBM versus $82 \%$ with allograft.

\section{FUTURE TRENDS}

Review of the current literature and preclinical data demonstrates that $\mathrm{DBM} / \mathrm{DBF}$ provide a promising graft alternative, especially when used as a graft extender. Critical evaluation of the literature does note limited level I clinical data supporting the efficacy of DBM, ${ }^{38}$ and, therefore, its widespread adaptation should be met with caution. Higher-powered level I studies are needed to truly determine the magnitude of effect DBM/DBF has compared with current graft extender options and graft options overall. Similarly, further studies are needed to better identify specific indications for or against the use of $\mathrm{DMB} / \mathrm{DBF}$ (ie, osteopenic/ osteoporotic patients).

Regarding market trends and future directions, there has been a shift in the market toward DBFbased products and away from products containing DBM particulates coupled with excipients, driven by the belief that excipients dilute DBM content because the excipient comprises a proportion of the final product. ${ }^{39}$ The introduction of numerous DBF products also followed the expiration of key patents and has allowed a number of newer products to be developed. Comparison of DBF fusion rates in a rat model indicates inter-product fusion variability, even among products noted to be $100 \%$ DBM by weight. ${ }^{39}$ These results likely indicate that proprietary preparation techniques may affect the actual osteoinductive properties (ie, BMP levels), as has been noted in previous DBM formulations. Further research is needed to elucidate these differences and their effect clinically.

An additional trend is towards procedure-specific grafts (eg, bags and boats for PLF) that simplify procedures, incorporate autograft/bone marrow 
aspirate to increase osteogenesis, improve process efficiency, and simplify and standardize the graft process. While these may decrease surgical time and potentially be easier to use, there are no clinical data to demonstrate sustained benefit.

Furthermore, the addition of live cells that have been predirected toward bone-forming lineages and the utilization of stem cells have gained increased interest, but lack clinical data to support their use.

\section{SUMMARY}

DBM and DBF are allograft alternatives used in spinal fusion procedures and are commonly used as autograft extenders. Preclinical evidence has demonstrated their ability for osteoinductivity, and clinical studies have shown equivalent fusion rates in the lumbar spine compared with the "gold standard" of ICBG. In the cervical spine, DBM/ DBF may be used to supplement interbody fusion in anterior-based procedures. While there are limited data regarding its use in deformity surgery, the use of $\mathrm{DBM} / \mathrm{DBF}$ as an autograft extender may be an improved alternative to traditional graft extenders, such as standard corticocancellous allograft and ceramics, given the improved biologic characteristics. Additional studies with higher levels of evidence are needed to support its clinical use with expanding indications. The incorporation of additional cell-based products remains an exciting opportunity for the use of $\mathrm{DBM} / \mathrm{DBF}$ in spine surgery.

\section{REFERENCES}

1. à Meek'ren J. Observationes Medico-Chirurgica. Amstelodami: Ex Officinâ Henrici \& Viduæ Theodori Boom; 1682.

2. Macewen W. Observations concerning transplantation of bone. Proc R Soc Lond. 1881;32:232-234.

3. Senn N. Senn on the healing of aseptic bone cavities by implantation of antiseptic decalcified bone. Ann Surg. 1889;10(5):352-368.

4. Urist MR, Strates BS. Bone morphogenetic protein. Journal of Dent Res. 1971;50(6):1392-1406.

5. Roberts TT, Rosenbaum AJ. Bone grafts, bone substitutes and orthobiologics: the bridge between basic science and clinical advancements in fracture healing. Organogenesis. 2012;8(4):114-124.

6. Drosos GI, Kazakos KI, Kouzoumpasis P, Verettas DA. Safety and efficacy of commercially available demineralised bone matrix preparations: a critical review of clinical studies. Injury. 2007;38(suppl 4):S13-S21.

7. Urist MR. Bone: formation by autoinduction. Science. 1965;150(19):893-899.

8. Flynn JM. Fracture repair and bone grafting. In: $O K U 10$ :
Orthopaedic Knowledge Update. 10th ed. Rosemont, IL: American Academy of Orthopaedic Surgeons; 2011:11-21.

9. Bae HW, Zhao L, Kanim LE, Wong P, Delamarter RB, Dawson EG. Intervariability and intravariability of bone morphogenetic proteins in commercially available demineralized bone matrix products. Spine (Phila Pa 1976). 2006;31(12):1299-1306; discussion 1307-1298.

10. Wildemann B, Kadow-Romacker A, Haas NP, Schmidmaier G. Quantification of various growth factors in different demineralized bone matrix preparations. J Biomed Mater Res A. 2007;81(2):437-442.

11. O'Leary RK, McBrayer PA, inventors; Osteotech, Inc, assignee. Flowable demineralized bone powder composition and its use in bone repair. US patent 50,733,731,991. September $21,1981$.

12. Dowd M, Dyke DG, inventors; Osteotech, Inc, assignee. Shaped materials derived from elongate bone particles. US patent 55,078,13 A. December 9, 1993.

13. Martin GJ, Boden SD, Titus L, Scarborough NL. New formulations of demineralized bone matrix as a more effective graft alternative in experimental posterolateral lumbar spine arthrodesis. Spine. 1999;24(7):637-645.

14. Kadam A, Millhouse PW, Kepler CK, et al. Bone substitutes and expanders in spine surgery: a review of their fusion efficacies. Int J Spine Surg. 2016;10:33.

15. Sassard WR, Eidman DK, Gray PM, et al. Augmenting local bone with Grafton demineralized bone matrix for posterolateral lumbar spine fusion: avoiding second site autologous bone harvest. Orthopedics. 2000;23(10):1059-1064; discussion 1064-1055.

16. Cammisa FP Jr, Lowery G, Garfin SR, et al. Two-year fusion rate equivalency between Grafton DBM gel and autograft in posterolateral spine fusion: a prospective controlled trial employing a side-by-side comparison in the same patient. Spine (Phila Pa 1976). 2004;29(6):660-666.

17. Vaccaro AR, Stubbs HA, Block JE. Demineralized bone matrix composite grafting for posterolateral spinal fusion. Orthopedics. 2007;30(7):567-570.

18. Kang J, An H, Hilibrand A, Yoon ST, Kavanagh E, Boden S. Grafton and local bone have comparable outcomes to iliac crest bone in instrumented single-level lumbar fusions. Spine (Phila Pa 1976). 2012;37(12):1083-1091.

19. Ahn DK, Moon SH, Kim TW, Boo KH, Hong SW. Demineralized bone matrix, as a graft enhancer of auto-local bone in posterior lumbar interbody fusion. Asian Spine $J$. 2014;8(2):129-137.

20. Baumann F, Krutsch W, Pfeifer C, Neumann C, Nerlich M, Loibl M. Posterolateral fusion in acute traumatic thoracolumbar fractures: a comparison of demineralized bone matrix and autologous bone graft. Acta Chir Orthop Traumatol Cech. 2015;82(2):119-125.

21. Ajiboye RM, Eckardt MA, Hamamoto JT, Plotkin B, Daubs MD, Wang JC. Outcomes of demineralized bone matrix enriched with concentrated bone marrow aspirate in lumbar fusion. Int J Spine Surg. 2016;10:35.

22. Chung HJ, Hur JW, Ryu KS, Kim JS, Seong JH. Surgical outcomes of anterior cervical fusion using deminaralized bone matrix as stand-alone graft material: single arm, pilot study. Korean J Spine. 2016;13(3):114-119.

23. Han S, Park B, Lim JW, et al. Comparison of fusion rate between demineralized bone matrix versus autograft in lumbar 
fusion: meta-analysis. J Korean Neurosurg Soc. 2020; 63(6):673680.

24. Fu TS, Wang IC, Lu ML, Hsieh MK, Chen LH, Chen WJ. The fusion rate of demineralized bone matrix compared with autogenous iliac bone graft for long multi-segment posterolateral spinal fusion. BMC Musculoskelet Disord. 2016;17:3.

25. Nam WD, Yi J. Bone union rate following instrumented posterolateral lumbar fusion: comparison between demineralized bone matrix versus hydroxyapatite. Asian Spine J. 2016;10(6):1149-1156.

26. Ricart PH, Gandhi SD, Geisinger J, Baker K, Park DK. Clinical and CT analysis of lumbar spine arthrodesis: betatricalcium phosphate versus demineralized bone matrix. $J \mathrm{Am}$ Acad Orthop Surg Glob Res Rev. 2018;2(9):e024.

27. Kim DH, Lee N, Shin DA, Yi S, Kim KN, Ha Y. Matched comparison of fusion rates between hydroxyapatite demineralized bone matrix and autograft in lumbar interbody fusion. J Korean Neurosurg Soc. 2016;59(4):363-367.

28. Buser Z, Brodke DS, Youssef JA, et al. Allograft versus demineralized bone matrix in instrumented and noninstrumented lumbar fusion: a systematic review. Global Spine J. 2018;8(4):396-412.

29. Ajiboye RM, Eckardt MA, Hamamoto JT, Sharma A, Khan AZ, Wang JC. Does age influence the efficacy of demineralized bone matrix enriched with concentrated bone marrow aspirate in lumbar fusions? Clin Spine Surg. 2018;31(1):E30-E35.

30. An HS, Simpson JM, Glover JM, Stephany J. Comparison between allograft plus demineralized bone matrix versus autograft in anterior cervical fusion. A prospective multicenter study. Spine (Phila Pa 1976). 1995;20(20):22112216.

31. Lee JC, Jang HD, Ahn J, Choi SW, Kang D, Shin BJ. Comparison of cortical ring allograft and plate fixation with autologous iliac bone graft for anterior cervical discectomy and fusion. Asian Spine J. 2019;13(2):258-264.

32. Park HW, Lee JK, Moon SJ, Seo SK, Lee JH, Kim SH. The efficacy of the synthetic interbody cage and Grafton for anterior cervical fusion. Spine (Phila Pa 1976). 2009;34(17):E591-595.

33. Shiban E, Nies M, Kogler J, et al. No correlation between radiological and clinical outcome 1 year following cervical arthrodesis. Acta Neurochir (Wien). 2018;160(4):845-853.

34. Xie Y, Li H, Yuan J, Fu L, Yang J, Zhang P. A prospective randomized comparison of PEEK cage containing calcium sulphate or demineralized bone matrix with autograft in anterior cervical interbody fusion. Int Orthop. 2015;39(6):1129-1136.
35. Yi J, Lee GW, Nam WD, et al. A prospective randomized clinical trial comparing bone union rate following anterior cervical discectomy and fusion using a polyetheretherketone cage: hydroxyapatite/B-tricalcium phosphate mixture versus hydroxyapatite/demineralized bone matrix mixture. Asian Spine J. 2015;9(1):30-38.

36. Price CT, Connolly JF, Carantzas AC, Ilyas I. Comparison of bone grafts for posterior spinal fusion in adolescent idiopathic scoliosis. Spine (Phila Pa 1976). 2003;28(8):793-798.

37. Weinzapfel B, Son-Hing JP, Armstrong DG, Blakemore LC, Poe-Kochert C, Thompson GH. Fusion rates after thoracoscopic release and bone graft substitutes in idiopathic scoliosis. Spine (Phila Pa 1976). 2008;33(10):1079-1083.

38. Van der Stok J, Hartholt KA, Schoenmakers DAL, Arts JJC. The available evidence on demineralised bone matrix in trauma and orthopaedic surgery: a systematic review. Bone Joint Res. 2017;6(7):423-432.

39. Russell N, Walsh WR, Lovric V, et al. In-vivo performance of seven commercially available demineralized bone matrix fiber and putty products in a rat posterolateral fusion model. Front Surg. 2020;7:10.

Disclosures and COI: Authors AJR and NAS have no disclosures. NLS: consultant and shareholder, TheraCell; AJC: employee and shareholder, TheraCell; FMP: royalties (Nuvasive, Medtronic), consulting (Nuvasive, SI-Bone, Stryker, Medtronic, Globus, Spinal Kinetics), and stock/options (Nuvasive, SI Bone, Surgio, Edge Surgical, Theracell, Spinal Simplicity, Augmedics).

Corresponding Author: Nicholas A. Shepard, MD, Department of Orthopaedic Surgery, Rush University Medical Center, 1611 W. Harrison Street, Chicago, IL 60612. Phone: (877) 632-6637; Email: nshepard88@gmail.com.

Published 30 April 2021

This manuscript is generously published free of charge by ISASS, the International Society for the Advancement of Spine Surgery. Copyright ( 2021 ISASS. To see more or order reprints or permissions, see http://ijssurgery.com. 